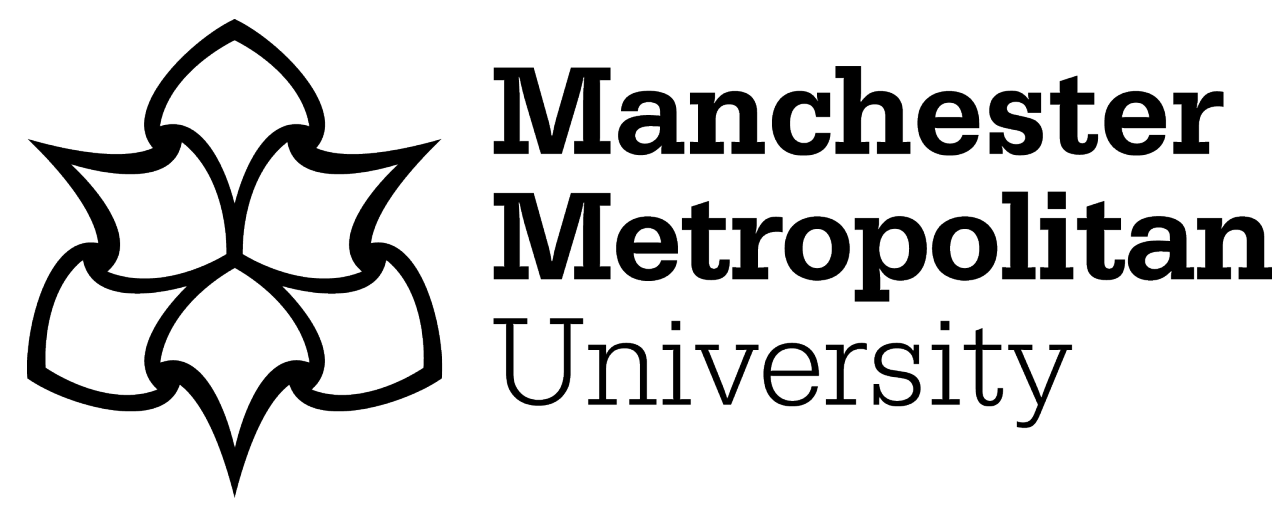

Canetti, D, Hirsch-Hoefler, S, Rapaport, C, Lowe, Robert and Muldoon, OT (2017) Psychological Barriers to a Peaceful Resolution: Longitudinal Evidence from the Middle East and Northern Ireland. Studies in Conflict and Terrorism, 41 (8). pp. 1-17. ISSN 1057-610X

Downloaded from: https://e-space.mmu.ac.uk/618846/

Version: Accepted Version

Publisher: Taylor \& Francis

DOI: https://doi.org/10.1080/1057610X.2017.1338051

Please cite the published version 
Running Head: Psychological Barriers to a Peaceful Resolution

\title{
Psychological Barriers to a Peaceful Resolution: Longitudinal Evidence from the Middle East and Northern Ireland
}

\author{
Daphna Canetti ${ }^{\mathrm{a}}$, Sivan Hirsch-Hoefler ${ }^{\mathrm{b}}$, Carmit Rapaport ${ }^{\mathrm{c}}$, Robert D. Lowe ${ }^{\mathrm{d}}$, and Orla T. \\ Muldoon ${ }^{\mathrm{e}}$.
}

${ }^{\text {a }}$ School of Political Science, University of Haifa, Haifa, Israel; ${ }^{b}$ Lauder School of Government, Diplomacy \& Strategy, Interdisciplinary Center Herzliya, Herzliya, Israel; ${ }^{c}$ Department of Geography and Environmental studies, University of Haifa, Haifa; ${ }^{\mathrm{d}}$ Department of Psychology, Manchester Metropolitan University, Manchester, England, UK; ${ }^{\mathrm{e}}$ Department of Psychology, University of Limerick, Limerick, Ireland.

This research was made possible, in part, by grants from the National Institute of Mental Health (R01 MH073687), the Israel Science Foundation (487/08) and the US-Israel Binational Science Foundation (2009460). Data collection in Northern Ireland was funded by a grant from the EU Special Support Programme for Peace and Reconciliation. We also thank JMCC in Ramallah and Mahshov in Israel for enabling our data collection.

Correspondence: Sivan Hirsch-Hoefler. Email: hsivan@idc.ac.il. Lauder School of Government, Diplomacy \& Strategy, Interdisciplinary Center Herzliya, Herzliya 4610101, Israel. 
Running Head: Psychological Barriers to a Peaceful Resolution

\section{Psychological Barriers to a Peaceful Resolution: Longitudinal Evidence from the Middle East and Northern Ireland}

Word Count: 8337

Does individual-level exposure to political violence prompt conciliatory attitudes? Does the answer vary by phase of conflict? The study uses longitudinal primary datasets to test the hypothesis that conflict-related experiences impact conciliation. Data was collected from Israeli Jews, Palestinians, and Protestants and Catholics in Northern Ireland. Across both contexts, and among both parties to each conflict, psychological distress and threat perceptions had a polarizing effect on conciliatory preferences. The study highlights that experiences of political violence are potentially a crucial source of psychological distress, and consequently, a continuing barrier to peace. This has implications in peacemaking, implying that alongside removing the real threat of violence, peacemakers must also work towards the social and political inclusion of those most affected by previous violence.

Keywords: Exposure to political violence, psychological distress, threat perception, conciliatory attitudes, Northern Ireland conflict, Israeli-Palestinian conflict 
Running Head: Psychological Barriers to a Peaceful Resolution

The past two decades - and particularly the period since 2001 - have seen a large number of studies examining the effects of terrorism and political violence on political attitudes. Some studies have shown that experiencing higher levels of terrorism increases individuals' tendency to vote for right-wing candidates and to engage in risk-seeking behaviors. ${ }^{1}$ The bulk of these studies examines the impact of political violence and terrorism at the level of the general populace. For example, experiences are measured at the community or national level and the consequence of these communal experiences assumed to predict individual sentiment. It is much rarer for respondents to be asked about their direct exposure to political violence, whilst also being questioned about their attitudes and perceptions. This has meant that studies have not always been able to take into account the participants' own individual suffering as a result of the conflict. ${ }^{2}$

That said, the sufferings of individuals directly exposed to prolonged conflict are likely to create psychological scars as well as societal ones. An emerging body of studies now show an impact of individual-level exposure to political violence (EPV) on several political attitudes, including: support for combatants in Afghanistan ${ }^{3}$, support for exclusionism $^{4}$ or intragroup retaliation in Israel $^{5}$, conservatism in the United States 6 , perceptions of intergroup threat in Northern Ireland ${ }^{7}$, and right-wing voting and riskseeking behaviors. ${ }^{8}$ To date the effect of EPV on attitudes towards reconciliation and peacebuilding has received little to no attention. This study is based on the premise that mental health is key to understanding the impact of conflict on peace/war attitudes (e.g., conciliatory attitudes). This study breaks new ground by utilizing an original comparative dataset from four groups with EPV - Israeli Jews, Palestinians, and Protestants and Catholics in Northern Ireland. The study offers important insights into two of the most 
Running Head: Psychological Barriers to a Peaceful Resolution

glaring case studies of violent protracted conflicts; both of which, though at different conflict-phases, fall short of attaining a stable peace. Uniquely, this comparative analysis benefits from a longitudinal design, allowing for the testing of causal claims about the impact of EPV at time 1 on time 2 attitudes to peace and compromise. Harnessing the power of this longitudinal design, the study controls for prior (time 1) attitudes and tests the direct impact of EPV on subsequent political attitudes (time 2).

\section{Exposure to Political Violence and Conciliatory Attitudes}

Convergent evidence suggests that political violence has many costs. As well as testing the hypothesis that EPV is linked to attitudes concerning peace and compromise, this paper considers two consequences of EPV that are frequently viewed separately. ${ }^{9}$ Literature on the mental cost of EPV is well established in psychology and psychiatry, as is the attitudinal consequence of violence in political science. Recently, scholars have begun to integrate the political and psychological foundations of conflict, with social psychologists utilizing the study of emotions ${ }^{10}$, societal norms ${ }^{11}$, racial prejudice ${ }^{12}$, identity ${ }^{13}$, and terror management theory. ${ }^{14}$ Empirical work by Hirsch-Hoefler et al. ${ }^{15}$, suggests that psychological constructs such as psychological distress and threat perceptions may be important drivers of the relationship between EPV and civilians' willingness to compromise for peace and support for diplomatic negotiations aimed at ending a prolonged conflict. Similarly, Lyall, Blair, and Imai ${ }^{16}$ found that individual-level outcomes were key micro-foundations of conflict in the Middle East.

Despite these recent studies, scholars are still in the dark as to how EPV influences conciliatory attitudes in different phases of the conflict process. In the context of prolonged 
Running Head: Psychological Barriers to a Peaceful Resolution

conflicts, garnering support for conciliatory policies is exceptionally challenging. It is therefore imperative that studies further explore the processes that act as either pathways or barriers to peace-building. The current study empirically examines the possibility that individuals exposed to political violence in intractable conflicts are likely to adopt more intransigent attitudes due to the effects of psychological distress and threat perceptions. Psychological distress is a well-established mental-health consequence of EPV. Associated symptoms include heightened anxiety, depression, and subjective insecurity. Unsurprisingly, the severity of psychological distress tends to rise with the severity of the EPV, as reflected in the extent to which the victim experiences disruption, loss, injury, or the death of a loved one. ${ }^{17}$ Threat perceptions, while related to psychological distress, is an independent construct which can be seen to operate in situations of political violence at least, at the group level. Threat perceptions refer specifically to appraisals of danger posed by the "other," or out-group, because of one's group identity. Therefore, though the distress may be experienced individually it arises due to perceptions of in-group security and as a result of identification with that group (i.e., sociotropic threat). ${ }^{18}$ Psychological distress and threat perceptions can arise from acute incidents of political violence, such as NYC 9/11, Madrid 3/11, London 7/7, or Oslo 7/22, ${ }^{19}$ as well as from repeated violence over prolonged periods. $^{20}$

Perceptions of threat may differ across the group's party to the conflict and across time in any given conflict. Available studies seem to be unable to sufficiently or precisely determine the political effect of individual-level EPV across different conflict settings. ${ }^{21}$ Most studies were carried out during ongoing conflict or post-conflict periods. Therefore, they fall short of providing a comparative perspective of the effect of EPV on conciliatory 
Running Head: Psychological Barriers to a Peaceful Resolution

attitudes during different phases of the conflict process, and what impact this may have on the prospects for peace-making. This study resolve this shortcoming by addressing a key theoretical question: What does looking at two phases of conflicts in tandem teach us about the broad consequences of conflict exposure and the prospects for future conflicts and peace negotiations? By examining two conflicts in different phases at the same time, the study is able to gain insight into the impact of EPV at different phases of conflict, and its broader impact on conflict resolution.

During peace-building, cease-fires and political agreements may weaken existential security threats; but the legacy of violence and animosity embedded in the collective identity and fostered by long-lasting psychological distress ${ }^{22}$ can powerfully maintain the perception of threat from the rival. Even during post-agreement phases of peace-building these perceptions may be transformed into symbolic threats to collective identity, and its social and political manifestations. ${ }^{23}$ Therefore it is expected that high levels of psychological distress and threat perception will persist in both minority and majority groups, regardless of the phase of the conflict. Given the asymmetrical power relations in both conflicts, the minority group would feel their security threatened by the majority group. On the other hand, the majority group would also experience increased threat perception, especially during times of increased conflict. It is hypothesized that this is a result of the psychological distress garnered from the potential loss of symbolic and material resources due to the conflict.

In essence, the study argues that at any stage of the peace-building process, perceptions of threat resulting from psychological distress can evoke conflict-supporting beliefs which can function as group-level threat buffers. Thus, individuals who have been 
Running Head: Psychological Barriers to a Peaceful Resolution

exposed to political violence may be less supportive of conciliatory policies throughout the process of peace-building.

In short, the study hypothesizes that across both contexts (i.e. an ongoing conflict vs. post-conflict), and among individuals on both sides of each conflict (i.e. minority group vs. majority), psychological distress and threat perceptions will mediate the (negative) relationship between EPV and conciliatory attitudes. The research model is presented in Figure 1.

Figure 1 about here

\section{Violence and Peace-Building in Israel/Palestine and Northern Ireland}

This study draws on unique longitudinal data from two regions where EPV has been both substantial and prolonged, namely Israel/Palestine (IL-PA) and Northern Ireland (NI) conflicts. Over the past two decades, the two conflicts have been coupled together in the literature as classic examples of protracted, intractable ethno-national conflicts. ${ }^{24}$ Both began turning toward peace-building during the 1990s, but where NI reached a conflict settlement (though it continues to confront challenges to building sustainable peace), the IL-PA conflict is still in a pre-agreement phase, oscillating between escalation and deescalation.

Northern Ireland's conflict between British Protestants and Irish Catholics had claimed over 3,500 fatalities by the turn of the century, more than half of them civilians, ${ }^{25}$ and over 30,000 civilians were injured between 1969 and $2003 .{ }^{26}$ Many people continue to live with long term disability and poor health as a consequence of the conflict, and few citizens have not been personally affected by it to some degree. ${ }^{27}$ The peace-building 
Running Head: Psychological Barriers to a Peaceful Resolution

process in Northern Ireland has taken a rocky road. The highly-acclaimed Belfast (Good Friday) agreement, which symbolically ended the conflict in 1998, was partially suspended for several years until several major difficulties were overcome in $2010 .{ }^{28}$ Although levels of violence dropped dramatically following the Belfast agreement, memories of past atrocities remain powerful, occasionally threatening the fragile political arrangements and the reconstruction of social relations.

In IL-PA, the 1993 Oslo Accords failed to evolve into a lasting peace agreement, and political violence continues to affect the lives of both Israeli Jews, and Palestinians. Since 2000 alone, 6,580 Palestinians have been killed by Israeli security forces, and 1,097 Israeli Jews have been killed by Palestinians ${ }^{29}$ - the latter mostly through suicide bombings during the Al Aqsa Intifada in 2001. Even during periods of negotiation, Palestinians experience the daily stress of occupation, and Israelis are constantly vigilant of suicide bombings or rocket attacks. This takes its toll on ordinary individuals' mental and physical health, ${ }^{30}$ with heightened levels of distress and threat perceptions present in both populations. ${ }^{31}$

In choosing these two conflicts, this study examines the consequences of EPV on conciliatory attitudes in a comparative perspective on different phases of peace-building following intractable conflict (Figure 1). The power of this comparative study is enhanced by the representativeness of its samples in both location and the cross-conflict context, which enables it to generalize our results. Additionally, the longitudinal data permit causal and inferential analyses about the impact of political violence on conciliatory attitudes across time.

\section{Research Design and Method}


Running Head: Psychological Barriers to a Peaceful Resolution

The study captures the political effect of EPV by examining four groups: Israeli Jews $(\mathrm{N}=167)$, Palestinians $(\mathrm{N}=124)$, and Protestants $(\mathrm{N}=61)$ and Catholics $(\mathrm{N}=68)$ in Northern Ireland.

\section{Sample and Procedure}

In the Israeli Jewish sample interviews were conducted by an experienced, computerized survey institute in Israel using trained telephone-survey interviewers. The response rate among eligible responders was 53\%. This compared favorably with studies in the U.S., especially given that the dialing methods in Israel, unlike the U.S., include business phones (approximately 10\%), which cannot be removed and are treated as failed attempts, and that

the higher rates in U.S. studies typically do not include non-answered phones. ${ }^{32}$ Those who agreed and were available were surveyed again approximately six months later $(80 \%$ reinterview rate).

The Palestinian sample was based on adult Palestinians living in the West Bank, Gaza Strip, and East Jerusalem. We employed a stratified 3-stage cluster random sampling strategy. First, 60 clusters were selected with populations of 1,000 or more individuals (after stratification by district and type of community - urban, rural, and refugee camp) with probabilities proportional to size. Next, 20 households in each of the chosen clusters were selected. The third stage involved selecting one individual in each household using Kish Tables (these tables provide within-household randomization of participants). After complete description of the study to the participants, written informed consent was obtained and they were paid the equivalent of about \$5 USD. Of the original sample, an 
Running Head: Psychological Barriers to a Peaceful Resolution

attempt was made to reach the 999 people who agreed to be contacted at 6-month followup. This sample yielded a response rate of $89 \%$.

In the NI sample, respondents in Wave 1 were recruited face to face in respondents' homes, using a paper-based questionnaire. A quota sampling mechanism was employed that considered the levels of violence experienced in the electoral ward, the religious composition of its residents, as well as levels of deprivation. ${ }^{33}$ Additionally, although the study refers to the 'Northern Ireland' sample, and uses as its main point of contrast 'Catholics' and 'Protestants', it must be acknowledged that the process of labelling categories has had a contentious and complicated history during the conflict and subsequent peace. As Whyte ${ }^{34}$ discusses, although principle distinctions in NI are often made on ethnoreligious background, the conflict is over national jurisdiction (with Unionists supporting NI within Britain and Nationalists arguing for the claim of the Republic of Ireland). Whilst the religious and political orientations of the population are roughly synonymous (Protestants/Unionist/British and Catholic/Nationalist/Irish) this can lead to a minority of Catholics and Protestants taking non-typical political positions. ${ }^{35}$

\section{Measures}

A closed-ended questionnaire was designed to incorporate four measures: EPV, psychological distress, threat perceptions, and conciliatory attitudes. Due to the different contexts, we have used slightly different items, however all scales were previously validated and tested. To overcome possible weaknesses in the cross-conflict comparison caused by the different conflict settings we kept, for each variable, the original context and meaning so that the answers will reflect the original meaning of the respondents. 
Running Head: Psychological Barriers to a Peaceful Resolution

Individual-level exposure to violence (EPV) was assessed using three items previously utilized by Lyall and colleagues. ${ }^{36}$ Respondents were asked whether they had experienced any of the following conflict-related events: (1) the death of a family member or friend; (2) witnessing an attack or being present at a site where there were injuries or fatalities; and/or (3) injury to oneself, a family member, or a friend. Responses were coded as 0 ("Not exposed to any of these events") or 1 ("Exposed to at least one event"). In the NI sample, the above three items were broken up into seven specific items to enhance the likelihood of recollection. As the final measures here too were dichotomous variables, the measures pertain to the exact same construct. The respondents were asked whether they had experienced any of the following conflict-related events: (1) caught in a bomb explosion; (2) caught in a shooting; (3) caught in a riot; (4) a witness of violent acts against others; (5) injured as a result of any incident; (6) affected by serious handicap/injury; (7) bereaved as a result of The Troubles. ${ }^{37}$ Responses were coded 0 if all seven items were answered "No" (i.e. "Not exposed to any of these events"), or 1 if any of the items received a "Yes" (i.e. "Exposed to at least one event"). As one kind of EPV does not necessarily preclude another, internal reliability was not calculated.

Psychological distress was assessed using a 17-item scale of posttraumatic stress symptoms. This format demonstrated $86 \%$ sensitivity and $78 \%$ specificity when compared to clinician interviews (PSS-I). ${ }^{38}$ It has been used in non-Western, low income regions, ${ }^{39}$ and within the Israeli (including both Palestinians and Jews; Hobfoll et al., 2006) and NI populations previously. ${ }^{40}$ Respondents were asked to report on the frequency of symptoms over the preceding month either in the context of The Troubles in Northern Ireland or the violence in the Israeli-Palestinian context, respondents were asked about symptoms such 
Running Head: Psychological Barriers to a Peaceful Resolution

as experiencing repeated dreams or nightmares. Scores were calculated as the average of all 17 responses. As the response scales for the various samples differed, the answers of each respondent were normalized to a score on a scale from 0 ("Not at all") to 1 ("Extremely frequent"). Cronbach's alpha for the scale in the current study was 0.87 for Israeli Jews, 0.84 for Palestinians, 0.96 for Catholics, and 0.96 for Protestants.

Threat perceptions were measured based on studies conducted in the United States, ${ }^{41}$ Northern Ireland, and the IL-PA context, ${ }^{42}$ using items related to the most pertinent current and future threats at the national level. ${ }^{43}$ For Israeli Jews and Palestinians the study asked respondents how concerned they were about the possibility that they, or a family member, might be hurt in an attack on the state of Israel/the Palestinian Territories. For the NI samples (Protestants and Catholics) the study asked respondents to what degree do they agree with the statement: "In certain areas I would be afraid of being identified as a Catholic/Protestant". Further, the answers of each respondent were normalized to a single threat perceptions score from 0 ("Not at all concerned") to 1 ("Extremely concerned") due to scale differences (Israeli Jews and Palestinians were measured on a four-range scale, while the NI sample on a five).

Conciliatory attitudes $^{44}$ the study referred to the specific context of the conflict for each sample. In IL-PA, the study measured attitudes toward compromise with the other side at the cost of a major concession. For Israeli Jews, this concession was accepting certain border arrangements. And for Palestinians, the concession was forgoing certain conditions such as sovereignty over parts of Jerusalem and return of refugees into Israel. In Northern Ireland, the study assessed the degree to which respondents supported the Stormont Assembly — a key institution arising from the 1998 Good Friday agreement 
Running Head: Psychological Barriers to a Peaceful Resolution

whose suspension from 2002 through 2007 led to political uncertainty. Again, differing scale ranges necessitated a normalization of the scale. For all four samples, answers ranged from 0 ("Strongly oppose") to 1 ("Strongly support" the relevant conciliatory policy). Across both conflicts the items measuring conciliatory attitudes related to a transition phase in the conflict, one that could be expected to change (in IL-PA), or did in fact change (in Northern Ireland), a temporary and unstable status quo into a presumably more permanent resolution.

Covariates/Control Variables: The study accounted for a number of variables that have been shown to be related to conciliatory attitudes in order to see the extent to which conciliatory attitudes were impacted by political violence above and beyond these control variables. The study controlled for sex (coded $1=$ male, $2=$ female), age (years) and conciliatory attitudes at wave one.

\section{Data Analysis}

The AMOS $6^{45}$ statistical program was used to conduct a multi-group structural equation modeling (SEM) analysis. Multi-group analysis allows testing for equivalence across groups simultaneously in one model. ${ }^{46}$ Multi-group analysis is based on the analysis of covariance (ANCOVA) structures ${ }^{47}$ while testing the invariance across groups. Moreover, this SEM method shows mediation or direction of causality by comparing them to their possible alternatives (i.e., inverse causality or a direct relationship instead of mediation). To examine the invariance or variance of political outcomes among the four conflictexposed groups, the study calculated maximum likelihood estimates for all models. These were evaluated by: (1) fit measures, namely $\chi^{2}$ and degrees of freedom, NFI, TLI, and CFI 
Running Head: Psychological Barriers to a Peaceful Resolution

in combination with RMSEA and ICA ${ }^{48}$; and (2) comparisons of nested models ${ }^{49}$ based on $\chi^{2}$ differences for constrained and unconstrained models. In all cases, political outcomes at time 2 were predicted whilst controlling for time 1 values on the same measure.

\section{Results}

Levels of EPV were high in the samples, with 58 percent of the respondents experiencing at least one type of exposure assessed. Table 1 presents descriptive statistics of the main research variables across the four groups. As can be seen in Table 1, conciliatory attitudes are higher for Catholics and Protestants than for Israelis and Palestinians in waves 1 and 2 $(.77, .73, .50, .26$ and $.80, .70, .48, .29$ respectively). Interestingly, over time, conciliatory attitudes were higher for Israelis and Protestants, but not for Catholics and Palestinians.

\section{Table 1 about here}

\section{Exposed vs. Not Exposed}

Table 2 presents means and standard deviations of the research variables by EPV. As expected, respondents who reported exposure to violence scored significantly higher on psychological distress and threat perceptions than those who had not been exposed. Exposed individuals were also less likely to exhibit conciliatory attitudes.

\section{Table 2 about here}

\section{Multi-Group Model}


Running Head: Psychological Barriers to a Peaceful Resolution

The study examined the role played by psychological distress and threat perceptions as mediators between EPV and conciliatory attitudes across the four samples. A multi-group analysis was employed to examine the proposed model in the four groups. First, the study examined whether the constrained model (assuming invariance of regression paths across the four groups) fit the data better than a free model, which assumed that no single structure fit all four groups. Next, the study presented robust analysis and examined alternative paths between the research variables to validate and reinforce the results, and to reject alternative explanations.

\section{Multi-Group Analysis}

First, the study examined a fully constrained model (all regression coefficients were constrained to be equal) in comparison with a fully free model (all regression coefficients varied across the four groups) to check for invariance in the model variables for all four groups. The results suggest the two models adequately describe the data (Fully free model: $\mathrm{X}^{2}=34.88, \mathrm{df}=28, \mathrm{CFI}=.966, \mathrm{TLI}=.898, \mathrm{RMSEA}=.024$; regression weights constrained to be equal across groups: $\left.\mathrm{X}^{2}=44.21, \mathrm{df}=37, \mathrm{CFI}=.964, \mathrm{TLI}=.919, \mathrm{RMSEA}=.022\right)$. However, the analysis found the difference between the regression-weight constrained model and the fully free one to be non-significant, suggesting that there is invariance between the two models, and the four groups are similar in their paths $\left(\Delta \mathrm{x}^{2}=9.33, \Delta \mathrm{df}=9, \mathrm{p}=.407\right)$. This led to the assumption that similar processes are at work among the four groups (See Figure 2).

Figure 2 about here 
Running Head: Psychological Barriers to a Peaceful Resolution

Next, the study tested for mediation using bias-corrected percentile bootstrapping (1000 bootstrap samples). The results show that psychological distress mediated the relationship between EPV and threat perceptions $(\beta=0.02 \mathrm{SE}=.006, \mathrm{CI}=0.01-0.03, \mathrm{p}=0.00)$, and that threat perceptions mediated the relationship between psychological distress and conciliatory attitudes $(\beta=-.0042, \mathrm{SE}=.018, \mathrm{CI}=-.08--.017, \mathrm{p}=0.00)$.

\section{Robust Analysis}

To eliminate the effect of other possible factors on the explained paths, the study constrained each path separately across all four groups (allowing the others to be free). As the general variance of the model does not relate to each path, but rather to the total model, constraining each path it strengthens the claim that the four groups are equal in their paths. It was found that each path (EPV to psychological distress, psychological distress to threat perceptions and threat perceptions to conciliatory attitudes) is similar across the four groups, as there is no significant worsening of the model fit (Table 3).

\section{Table 3 about here}

Finally, the study examined whether alternative models provide a better fit for the data. To do so, an alternative model was considered where EPV leads to threat perceptions leading to psychological distress, which then affects conciliatory attitudes (Model 2). The regression coefficients are presented in Figure 3. As can be seen, the model fits the data poorly, and psychological distress does not affect conciliatory attitudes (Table 4).

Figure 3 about here 
Running Head: Psychological Barriers to a Peaceful Resolution

Table 4 about here

The analyses largely supported the hypotheses, and described the significant effect of EPV on psychological distress and threat perceptions at time 1. This led to decreased conciliatory attitudes at time 2 in all four populations studied. The alternative model examining different paths of influence between EPV and conciliatory attitudes showed a poor fit for the data, reinforcing the suggested model.

It should be noted that the analyses cannot rule out potential confounding effects from two factors which differ between the two case studies: (a) the time elapsed since exposure to violent incidents, and (b) the degree of symmetry in power relations between the two sides. With respect to the first, at least a decade passed between the end of most conflict-related violence in NI and the data collection, while in IL-PA the violence remains ongoing. It is not unreasonable to imagine that the passage of time could have tempered the association between EPV and psychological distress in Northern Ireland. However, no significant differences were found among the four groups regarding our hypothesized theoretical model, implying that exposure to conflict-related violence continues to affect political attitudes during the long process of peace-building even after a political agreement is achieved.

The asymmetrical nature of the IL-PA conflict can explain the higher levels of EPV in the Palestinian sample (see Table 1). The findings also support earlier work indicating similar levels of threat perceptions between Israeli Jews and Palestinians. With respect to symmetry in power relations, one might presume that their status as the stronger party ${ }^{50}$ would give Israeli Jews a greater sense of control, leading to lower perceptions of threat. 
Running Head: Psychological Barriers to a Peaceful Resolution

In Northern Ireland, threat amongst the Protestant majority group might be presumed to be higher than the minority group. However, previous research has shown that despite the asymmetrical power relations Israeli Jews exhibit high threat perceptions, especially during times of intense violence ${ }^{51}$, as did Protestants in Northern Ireland. ${ }^{52}$ This perceived threat can be linked to potential loss of symbolic status and resources that majority groups experience during conflict. Importantly, this perception reflects the fact that the threat, as measured here, is a collective threat to the majority group - in this case the Protestants and Jews. In this regard, perceived collective threat is very much a link between individual psychological distress because of political violence at the micro level, and wider macrolevel social and political attitudes.

\section{Discussion and Conclusion}

The political science literature aimed at understanding the psycho-political impact of exposure to violence on citizens in conflict zones is limited and ambiguous in its findings. This paper emphasizes the centrality of personal exposure to political violence - an aspect of human experience often ignored in political scholarship - and reaffirms the need for psycho-political approaches to the study of how political violence affects the politics of peace. The study argues that, in any given context, individuals differ in their experiences of conflict, their levels of psychological distress and threat perceptions, and, consequently, their political attitudes. In short, the study displays that greater conflict exposure amplifies psychological distress, which in turn increases threat perceptions and thereby makes individuals less likely to adopt conciliatory attitudes. 
Running Head: Psychological Barriers to a Peaceful Resolution

Drawing on data from four samples representing two case studies, the study examines psychological distress and threat perceptions following citizens' exposure to violence in IL-PA and NI. Across both contexts, and among individuals on both sides of each conflict, the cross-lagged model shows that EPV increases psychological distress and threat perceptions, and that threat perceptions reduced willingness to support peacebuilding. To put it succinctly, "violence begets violence." This is contrary to the view often promulgated by both state and non-state actors that violence is a necessary condition for political solutions. ${ }^{53}$ The current data provide powerful evidence that in situations of prolonged political conflict, EPV will reduce conciliatory attitudes and therefore the possibility of building peace. These findings contribute to the emerging literature on barriers to peace ${ }^{54}$, which highlights how conflict-related violence continues to affect political attitudes during the long process of peace-building, even after a political agreement is achieved and the violence has stopped.

These findings accentuate the key role played by collective threat perceptions, and reaffirm the importance of individual exposure to violent events in forming subsequent political attitudes. One potential explanation for this strong connection between exposure and political views is the "shattered assumptions" approach. ${ }^{55}$ According to this theory, traumatic events challenge many of the basic assumptions individuals hold about the world or themselves. These challenges trigger enhanced perceptions of the world as threatening, and a correspondingly strong desire to reduce this threat (and the fear it induces) through increased militancy towards the perceived source of threat - the conflict out-group.

The findings also contribute to the growing literature on barriers to conflict resolution. Recent work by Bar-Tal, Halperin and their colleagues ${ }^{56}$ elaborates on both the 
Running Head: Psychological Barriers to a Peaceful Resolution

mechanism and the effects of socio-psychological barriers (i.e., ideological conflictsupporting beliefs and inter-group emotions on conflict-related attitudes). While that emerging line of research focuses mainly on cognitive and emotional phenomena, this study's findings point to the powerful role of conflict-related experiences (specifically EPV) as a potential barrier to peace-building. Indeed, the fact that EPV continued to be a source of psychological distress and threat perceptions among the sample in NI ten years after a political agreement, exemplifies how the effects of conflict may continue to interfere with progress towards peace despite official settlements. Furthermore, this reaffirms that minimizing threat perceptions between groups is central to the development of stable peace and reconciliation.

On the practical level, this study's findings highlight the importance of efforts to help victims of conflict cope with pervasive traumatic experiences despite significant separation in time from occurrence. This study points to the importance of the experiences of those most affected by political violence for the development of peace in intractable conflict. This study's findings suggest that those who are most exposed to political violence are also those who are likely to feel most threatened by the out-group, and therefore the least likely to engage in compromise or reconciliation. Moreover, a further consequence of this is that these groups can also feel both socially and politically isolated from those seeking resolution of the conflict. Thus, while removing the real threat of violence is crucial to progress, it is not sufficient. Peace-making also requires ensuring the social and political inclusion of those who have been most affected by the violence through acknowledgment and legitimization of their losses. 
Running Head: Psychological Barriers to a Peaceful Resolution

Indeed, recent history in both NI and IL-PA ${ }^{57}$ shows that agreements between policymakers are insufficient for reconciliation and stable peace. Rather, such agreements must be accompanied by people-to-people dynamics that both reflect and engender social and psychological change. ${ }^{58}$ Put differently, peace depends on a social infrastructure capable of sustaining formal political agreements, which must itself be based on recognition of EPV's psychological and political toll. 
Running Head: Psychological Barriers to a Peaceful Resolution

\section{Tables}

Table 1. Descriptive statistics of research variables, and comparison between Israeli Jews,

Palestinians, and Northern Ireland Catholics and Protestants

\begin{tabular}{|c|c|c|c|c|c|c|c|c|c|c|}
\hline & $\begin{array}{l}\text { Israeli } \\
(\mathrm{N}=16\end{array}$ & & $\begin{array}{l}\text { Palest } \\
(\mathrm{N}=12\end{array}$ & & $\begin{array}{l}\text { Prote } \\
(\mathrm{N}=6\end{array}$ & & $\begin{array}{l}\text { Catho } \\
(\mathrm{N}=68\end{array}$ & & $f$ test & \\
\hline Variable & $\mathrm{M}$ & SD & $\mathrm{M}$ & SD & $\mathrm{M}$ & SD & $\mathrm{M}$ & SD & $f$ & $P$ \\
\hline $\begin{array}{l}\text { Exposure to violence } \\
\text { (W1) }\end{array}$ & .47 & .50 & .65 & .48 & .59 & .49 & .69 & .46 & 4.82 & $<.001$ \\
\hline $\begin{array}{l}\text { Psychological distress } \\
\text { (W1) }\end{array}$ & .08 & .10 & .32 & .12 & .06 & .13 & .09 & .16 & 107.84 & $<.001$ \\
\hline $\begin{array}{l}\text { Threat perceptions } \\
\text { (W1) }\end{array}$ & .74 & .25 & .74 & .25 & .69 & .22 & .71 & .24 & .707 & $<.001$ \\
\hline $\begin{array}{l}\text { Conciliatory attitudes } \\
\text { (W2) }\end{array}$ & .50 & .30 & .26 & .12 & .73 & .19 & .77 & .15 & 100.06 & $<.001$ \\
\hline Gender $(\%)$ & $\begin{array}{l}45.5 \% \\
\text { (male) }\end{array}$ & & $\begin{array}{l}53 \% \\
\text { (male) }\end{array}$ & & $\begin{array}{l}50 \% \\
\text { (male) }\end{array}$ & & $\begin{array}{l}57 \% \\
\text { (male) }\end{array}$ & & & \\
\hline Age (years) & 46.6 & 16.64 & 35.8 & $\begin{array}{l}12.7 \\
1\end{array}$ & 49.8 & 15.44 & 46.8 & 15.17 & & \\
\hline $\begin{array}{l}\text { Conciliatory attitudes } \\
\text { (w1) }\end{array}$ & .48 & .29 & .29 & .18 & .70 & .17 & .80 & .13 & & \\
\hline
\end{tabular}

Table 2. Comparison between exposed and non-exposed participants, entire sample

\begin{tabular}{|lcccccc|}
\hline Entire sample & $\begin{array}{c}\text { Exposed to political } \\
\text { violence } \\
\text { Independent variables }\end{array}$ & $\begin{array}{c}\text { Not exposed to } \\
\text { political violence } \\
(\mathrm{N}=177)\end{array}$ & & \\
\cline { 2 - 5 } & $M$ & $S D$ & $M$ & $S D$ & $t$ & $P$ \\
\hline Psychological distress (W1) & .18 & .18 & .10 & .13 & 4.76 & $<.00$ \\
Threat perceptions (W1) & .75 & .25 & .70 & .23 & 2.16 & $<0.05$ \\
Conciliatory attitudes (W2) & .49 & .30 & .54 & .28 & -1.68 & $<0.10$ \\
\hline
\end{tabular}




\section{Running Head: Psychological Barriers to a Peaceful Resolution}

Table 3. Goodness of fit indices and model comparison across paths (constrained separately)

\begin{tabular}{lcccc}
\hline Path & CFI & $\Delta \mathrm{X}^{2}$ & $\Delta \mathrm{df}$ & $\mathrm{P}$ \\
\hline EPV to psychological distress & .96 & 2.70 & 3 & .440 \\
\hline psychological distress to threat perceptions & .96 & 4.18 & 3 & .243 \\
\hline threat perceptions to conciliatory attitudes & .96 & 2.44 & 3 & .485 \\
\hline
\end{tabular}

$\mathrm{EPV}=$ Exposure to violence

Table 4. Goodness of fit indices of alternative model

\begin{tabular}{|c|c|c|c|c|c|c|}
\hline Model & $\overline{\mathrm{X}^{2}}$ & $\mathrm{Df}$ & CFI & $\begin{array}{l}\text { RMSE } \\
\text { A }\end{array}$ & $\begin{array}{l}\Delta \mathrm{X}^{2} \\
\text { (compare } \\
\mathrm{d} \text { with } \\
\text { fully free) }\end{array}$ & $\begin{array}{l}P \\
\text { (compared } \\
\text { with fully } \\
\text { free) }\end{array}$ \\
\hline $\begin{array}{l}\text { exposure }->\text { threat } \\
\text { perceptions }->\text { psy distress }-> \\
\text { conciliatory attitudes }\end{array}$ & 57.76 & 37 & .897 & .0 .037 & 12.861 & .169 \\
\hline
\end{tabular}




\section{Running Head: Psychological Barriers to a Peaceful Resolution}

\section{Figures}

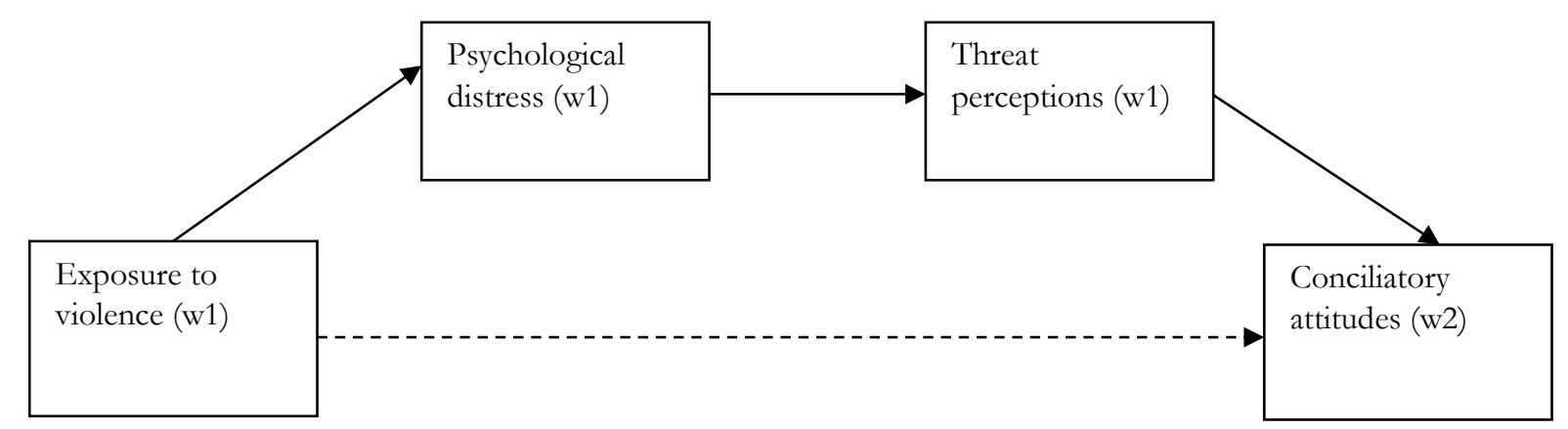

Figure 1. Hypothesized model explaining changes in attitudes towards peace as a result of exposure to ongoing conflict

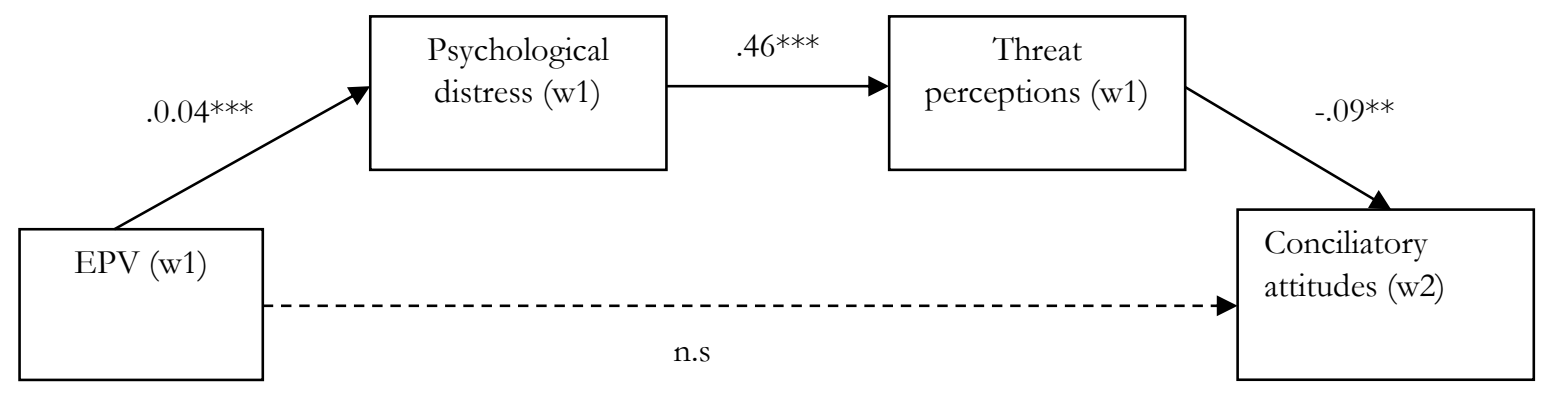

Figure 2. Psychological distress leading to threat perceptions leading to more negative conciliatory attitudes (unstandardized coefficients) 
Running Head: Psychological Barriers to a Peaceful Resolution

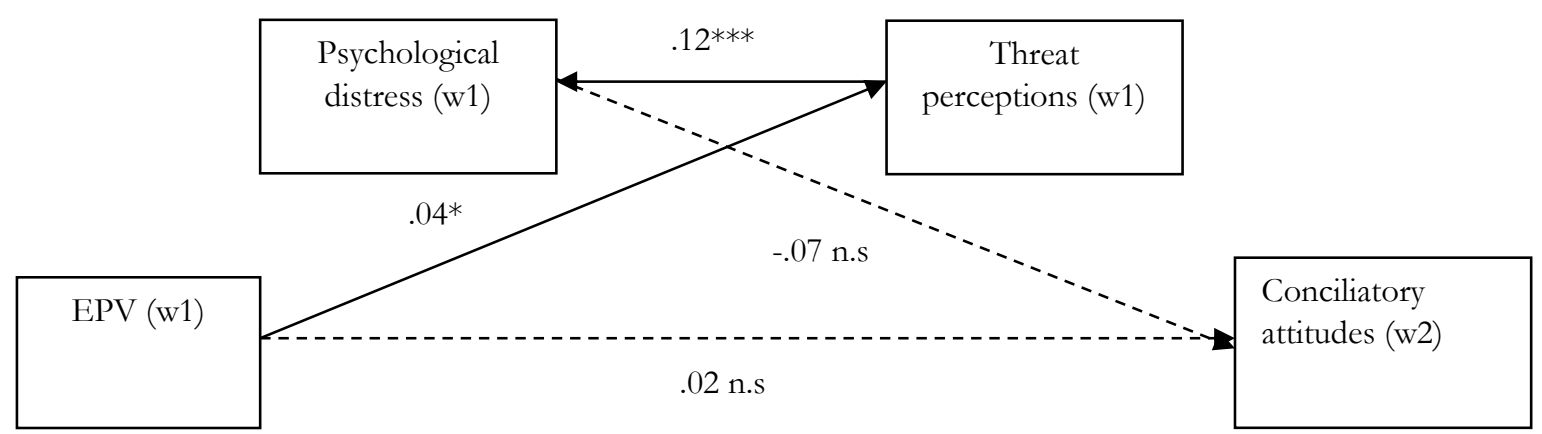

Figure 3. Regression path for all alternative models 
Running Head: Psychological Barriers to a Peaceful Resolution

\section{Notes}

${ }^{1}$ Claude Berrebi and Esteban F. Klor, "Are Voters Sensitive to Terrorism? Direct Evidence from the Israeli Electorate," American Political Science Review 102(3) (2008), pp. 279301; Eric D. Gould and Esteban F. Klor, "Does Terrorism Work?" The Quarterly Journal of Economics 125(4) (2010), pp. 1459-1510; David A. Jaeger and Daniele M. Paserman, "The Cycle of Violence? An Empirical Analysis of Fatalities in the Palestinian-Israeli Conflict," The American Economic Review 98(4) (2008), pp. 1591-1604; Jose G. Montalvo, "Voting after the Bombings: A Natural Experiment on the Effect of Terrorist Attacks on Democratic Elections," Review of Economics and Statistics 93(4) (2011), pp. 1146-1154; Maarten J. Voors, Eleonora E.M., Nillesen, Philip Verwimp, Erwin H. Bulte, Robert Lensink and Daan P. Van Soest, "Violent Conflict and Behavior: A Field Experiment in Burundi," The American Economic Review 102(2) (2012), pp. 941-964.

${ }^{2}$ Darren W Davis and Brian D. Silver, "Civil Liberties vs. Security: Public Opinion in the Context of the Terrorist Attacks on America," American Journal of Political Science 48(1) (2004), pp. 28-46; Ronald Inglehart, Mansoor Moaddel, and Mark Tessler, "Xenophobia and In-Group Solidarity in Iraq: A Natural Experiment on the Impact of Insecurity," Perspectives on Politics 4(3) (2006), pp. 495-505; Niklas Jakobsson and Svein Blom, "Did the 2011 Terror Attacks in Norway Change Citizens' Attitudes toward Immigrants?" International Journal of Public Opinion Research 26(4) (2014), pp. 475486; Jennifer L. Merolla and Elizabeth J. Zechmeister, Democracy at Risk: How Terrorist Threats Affect the Public. (Chicago: University of Chicago Press, 2009). 
${ }^{3}$ Jason Lyall, Graeme Blair, and Kosuke Imai, "Explaining Support for Combatants during Wartime: A Survey Experiment in Afghanistan," American Political Science Review 107(4) (2013), pp. 679-705.

${ }^{4}$ Daphna Canetti-Nisim, Eran Halperin, Keren Sharvit, and Stevan E. Hobfoll, "A New Stress-Based Model of Political Extremism Personal Exposure to Terrorism, Psychological Distress, and Exclusionist Political Attitudes," Journal of Conflict Resolution 53(3) (2009), pp. 363-389.

${ }^{5}$ Thomas Zeitzoff, "Anger, Exposure to Violence, and Intragroup Conflict: A "Lab in the Field" Experiment in Southern Israel," Political Psychology 35(3) (2014), pp. 309-335.

${ }^{6}$ George A. Bonanno and John T. Jost, "Conservative Shift among High-Exposure Survivors of the September 11th Terrorist Attacks," Basic and Applied Social Psychology 28(4) (2006), pp. 311-323.

${ }^{7}$ Katharina Schmid and Orla T. Muldoon, "Perceived Threat, Social Identification, and Psychological Well- Being: The Effects of Political Conflict Exposure," Political Psychology 36(1) (2015), pp. 75-92.

${ }^{8}$ Claude Berrebi and Esteban F. Klor, "Are Voters Sensitive to Terrorism? Direct Evidence from the Israeli Electorate," American Political Science Review 102(3) (2008), pp. 279301; Eric D. Gould and Esteban F. Klor, "Does Terrorism Work?" The Quarterly Journal of Economics 125(4) (2010), pp. 1459-1510; Jose G. Montalvo, "Voting after the Bombings: A Natural Experiment on the Effect of Terrorist Attacks on Democratic Elections," Review of Economics and Statistics 93(4) (2011), pp. 1146-1154; Maarten J. Voors, Eleonora E.M. Nillesen, Philip Verwimp, Erwin H. Bulte, Robert Lensink, and 
Daan P. Van Soest, "Violent Conflict and Behavior: A Field Experiment in Burundi," The American Economic Review 102(2) (2012), pp. 941-964; Getmansky, Anna, and Thomas Zeitzoff. "Terrorism and voting: The effect of rocket threat on voting in Israeli elections." American Political Science Review 108(03) (2014), pp. 588-604.

${ }^{9}$ Orla T. Muldoon, "Understanding the Impact of Political Violence in Childhood: A Theoretical Review using a Social Identity Approach," Clinical Psychology Review 33(8) (2013), pp. 929-939.

${ }^{10}$ Smadar Cohen-Chen, Eran Halperin, Richard J. Crisp, and James J. Gross, "Hope in the Middle East: Malleability Beliefs, Hope, and the Willingness to Compromise for Peace," Social Psychological and Personality Science 5(1) (2014), pp. 67-75; Eran Halperin, "Group-Based Hatred in Intractable Conflict in Israel," Journal of Conflict Resolution 52(5) (2008), pp. 713-736; Jennifer S. Lerner, Roxana M. Gonzalez, Deborah A. Small, and Baruch Fischhoff, "Effects of Fear and Anger on Perceived Risks of Terrorism a National Field Experiment," Psychological science 14(2) (2003), pp. 144-150.

11 Daniel Bar-Tal, "From Intractable Conflict through Conflict Resolution To Reconciliation: Psychological Analysis," Political Psychology 21(2) (2012), pp. 351-365.

${ }^{12}$ Agustin Echebarria- Echabe and Emilia Fernández- Guede, "Effects of Terrorism on Attitudes and Ideological Orientation," European Journal of Social Psychology 36(2) (2006), pp. 259-265.

${ }^{13}$ Orla T. Muldoon, "Understanding the Impact of Political Violence in Childhood: A Theoretical Review using a Social Identity Approach," Clinical Psychology Review 33(8) (2013), pp. 929-939; Orla T. Muldoon, Katharina Sdhmid, and Ciara Downes, "Political 
Violence and Psychological Well-being: The Role of Social Identity," Applied Psychology 58(1) (2009), pp. 129-145; Orla T. Muldoon and Ciara Downes, "Social Identity and Prevalence of PTSD in Northern Ireland," British Journal of Psychiatry 191(2) (2007), pp. 146-149; Orla T. Muldoon and Robert Lowe, "Social identity, Groups and PTSD," Political Psychology 33(2) (2012), pp. 259-273.

14 Jeff Greenberg, Tom Pyszczynski, and Sheldon Solomon, "The Causes and Consequences of a Need for Self-Esteem: A Terror Management Theory," In Roy F. Baumeister, ed., Public Self and Private Self, (New York: Springer New York, 1986), pp. 189-212.

${ }^{15}$ Sivan Hirsch-Hoefler, Daphna Canetti, Carmit Rapaport, and Stevan E. Hobfoll, "Conflict will Harden your Heart: Exposure to Violence, Psychological Distress, and Peace Barriers in Israel and Palestine," British Journal of Political Science 46(4) (2014), pp. 115.

${ }^{16}$ Jason Lyall, Graeme Blair, and Kosuke Imai, "Explaining Support for Combatants during Wartime: A Survey Experiment in Afghanistan," American Political Science Review 107(4) (2013), pp. 679-705.

${ }^{17}$ Stevan E. Hobfoll, Daphna Canetti-Nisim, and Robert J. Johnson, "Exposure to Terrorism, Stress-Related Mental Health Symptoms, and Defensive Coping among Jews and Arabs in Israel," Journal of Consulting and Clinical Psychology 74(2) (2006), pp. 207218.

${ }^{18}$ Daphna Canetti-Nisim, Gal Ariely, and Eran Halperin, "Life, Pocketbook, or Culture: The Role of Perceived Security Threats in Promoting Exclusionist Political Attitudes 
Running Head: Psychological Barriers to a Peaceful Resolution

toward Minorities in Israel," Political Research Quarterly 61(1) (2008), pp. 90-103; Leonie Huddy, Stanley Feldman, Theresa Capelos, and Colin Provost, "The Consequences of Terrorism: Disentangling the Effects of Personal and National Threat," Political Psychology 23(3) (2002), pp. 485-509; Blake M. Riek, Eric W. Mania, and Samuel L. Gaertner, "Intergroup Threat and Outgroup Attitudes: A Meta-Analytic Review," Personality and Social Psychology Review 10(4) (2006), pp. 336-353.

19 Leonie Huddy and Stanley Feldman, "Americans respond politically to 9/11: Understanding the impact of the terrorist attacks and their aftermath," American Psychologist 66(6) (2011), pp. 455-467; Niklas Jakobsson and Svein Blom, "Did the 2011 Terror Attacks in Norway Change Citizens' Attitudes toward Immigrants?" International Journal of Public Opinion Research 26(4) (2014), pp. 475-486; Jennifer S. Lerner, Roxana M. Gonzalez, Deborah A. Small, and Baruch Fischhoff, "Effects of Fear and Anger on Perceived Risks of Terrorism a National Field Experiment," Psychological science 14(2) (2003), pp. 144-150; James G. Rubin, Chris R. Brewin, Neil Greenberg, Jamie Hacker Hughes, John Simpson, and Simon Wessely, "Enduring Consequences of Terrorism: 7-Month Follow-Up Survey of Reactions to the Bombings in London on 7 July 2005," The British Journal of Psychiatry 190(4) (2007), pp. 350-356.

${ }^{20}$ Ed Cairns, Children and Political Violence (Blackwell Publishing, 1996); Despite claims of systematic desensitization, large representative samples that are powered to detect the effects of cumulative trauma exposure on mental health suggest that greater past traumas increase the risk of developing PTSD from a subsequent traumatic event (see Breslau et al. 1999: 902-907). Thus, findings are not clearly suggestive of a desensitization hypothesis. Although some may become desensitized, studies on IL-PA affected civilians have shown 
that the more an individual was exposed, the more likely he or she was to fall into a group with a worse trajectory (i.e., chronic poor mental health) (see Hobfoll et al., 2006).

${ }^{21}$ Finola Ferry, Brendan Bunting, Samuek Murphy, Siobhan ONeill, Dan Stein, and Karestan Koenen "Traumatic Events and Their Relative PTSD Burden in Northern Ireland: a Consideration of the Impact of the 'Troubles'," Social Psychiatry and Psychiatric Epidemiology 49(3) (2014), pp. 435-446; Daphna Canetti, Brian J. Hall, Carmit Rapaport, and Carly Wayne, "Exposure to Political Violence and Political Extremism," European Psychologist 18 (2013), pp. 263-272; Daphna Canetti, Brian J. Hall, Talya Greene, Jeremy C. Kane, and Stevan E. Hobfoll, "Improving Mental Health is Key to Reduce Violence in Israel and Gaza," The Lancet 384(9942) (2014), pp. 493-494; David Mendeloff, "Trauma and Vengeance: Assessing the Psychological and Emotional Effects of Post-Conflict Justice," Human Rights Quarterly 31(3) (2009), pp. 592-623; Kristin M. Bakke, John O'Loughlin, and Michael D. Ward, "Reconciliation in Conflict-Affected Societies: Multilevel Modeling of Individual and Contextual Factors in the North Caucasus of Russia," Annals of the Association of American Geographers 99(5) (2009), pp. 1012-1021; Masi Noor, Rupert Brown, Roberto Gonzalez, Jorge Manzi, and Christopher Alan Lewis, "On Positive Psychological Outcomes: What Helps Groups with a History of Conflict to Forgive and Reconcile with Each Other?" Personality and Social Psychology Bulletin 34(6) (2008), pp. 819-832; Masi Noor, Nurit Shnabel, Samer Halabi, and Arie Nadler "When Suffering Begets Suffering the Psychology of Competitive Victimhood between Adversarial Groups in Violent Conflicts," Personality and Social Psychology Review 16(4) (2012), pp. 351-374. 
Running Head: Psychological Barriers to a Peaceful Resolution

${ }^{22}$ Daniel Bar-Tal, Intractable Conflicts: Socio-Psychological Foundations and Dynamics (New York: Cambridge University Press, 2013).

${ }^{23}$ Daphna Canetti-Nisim, Eran Halperin, Keren Sharvit, and Stevan E. Hobfoll, "A New Stress-Based Model of Political Extremism Personal Exposure to Terrorism, Psychological Distress, and Exclusionist Political Attitudes," Journal of Conflict Resolution 53(3) (2009), pp. 363-389.

${ }^{24}$ Guy Ben-Porat, The Failure of the Middle East Peace Process? A Comparative Analysis of Peace Implementation in Israel/Palestine, Northern Ireland and South Africa (New York: Springer, 2008); Hermann Buhr Giliomee and Jannie Gagiano, The Elusive Search for Peace: South Africa, Israel and Northern Island [ie Ireland] (USA: Oxford University Press, 1990); Ian Lustick, Unsettled States, Disputed Lands: Britain and Ireland, France and Algeria, Israel and the West Bank-Gaza (Cornell University Press, 1993); Yoav Peled, The Challenge of Ethnic Democracy: The State and Minority Groups in Israel, Poland and Northern Ireland (New York: Routledge, 2013); Moran Yarchi, "Does Using 'Imagefare' as a State's Strategy in Asymmetric Conflicts Improve its Foreign Media Coverage? The Case of Israel," Media, War \& Conflict 9(3) (2016), pp. 290-305.

${ }^{25}$ See Malcom Sutton Index of Deaths from the conflict in Ireland (Malcolm Sutton, Bear in Mind these Dead: An Index of Deaths from the Conáict in Ireland 1969-1993 (Belfast: Beyond the Pale Publications, 1994)).

${ }^{26} \mathrm{Ibid}$ 
${ }^{27}$ Bernadette C. Hayes and Ian McAllister, "Sowing Dragon's Teeth: Public Support for Political Violence and Paramilitarism in Northern Ireland," Political Studies 49(5) (2001), pp. 901-922.

${ }^{28}$ Guelke, Adrian, Politics in Deeply Divided Societies (UK \& USA: Polity Press, 2012).

${ }^{29}$ See Btselem Statistics (B'Tselem - The Israeli Center for Human Rights. Attacks on Israeli civilians by Palestinians. January $1, \quad 2011$. http://www.btselem.org/israeli_civilians/qassam_missiles\#data (accessed December 1, 2012)).

${ }^{30}$ M. Nicole Heath, Brian J. Hall, Daphna Canetti, and Stevan E. Hobfoll, "Exposure to Political Violence, Psychological Distress, Resource Loss, and Benefit Finding as Predictors of Domestic Violence among Palestinians," Psychological Trauma 5(4) (2012), pp. 366-376.

${ }^{31}$ Alean Al-Krenawi, John R. Graham, and Yaniv Kanat-Maymon, "Analysis of Trauma Exposure, Symptomatology and Functioning in Jewish Israeli and Palestinian Adolescents," The British Journal of Psychiatry 195(5) (2009), pp. 427-432; Daphna Canetti-Nisim, Eran Halperin, Keren Sharvit, and Stevan E. Hobfoll, "A New Stress-Based Model of Political Extremism Personal Exposure to Terrorism, Psychological Distress, and Exclusionist Political Attitudes," Journal of Conflict Resolution 53(3) (2009), pp. 363-389; Zahava Solomon and Tamar Lavi, "Israeli Youth in the Second Intifada: PTSD and Future Orientation," Journal of the American Academy of Child \& Adolescent Psychiatry 44(11) (2005), pp. 1167-1175. 
${ }^{32}$ Galea, S. Ahern, J., H. Resnick, D Kilpatrick, M. Bucuvalas, J Gold, and D Vlahov. "Psychological sequelae of the September 11 terrorist attacks in New York City." New England Journal of Medicine 346 (2002): 982-987.

${ }^{33}$ Selection of electoral wards of which there are currently 582 in NI was informed by the 1969-1998 dataset of Troubles-related deaths in NI collated by Fay, Morrissey \& Smyth (1999). Using Fay et al.'s original data (Smyth, personal communication) geographical experience of violence was determined through calculations of deaths per 1000 population in electoral wards in Northern Ireland. The top 15\% (85 wards) were marked as 'High experience'. The 122 wards where "Deaths per 1000" was zero were classified as 'Low experience' wards. Electoral wards that were both high and low experience were included. Urbanisation was also controlled for as a potential confounding variable. It was defined by using the number of persons per hectare (npph), based on the 2001 Census of Population statistics. When npph was below one, the ward was defined as 'rural', when above one it was defined as 'urban'. The wards were divided into rural and urban districts, and five high-experience rural and five high-experience urban wards were selected using the random sampling function in SPSS. These were matched against low-experience wards using the rural/urban index and deprivation scores determined from Robson, Bradford, \& Deas (1994), as used in the original Fay et al (1999) dataset. A total of 334 respondents were sampled across these areas.

${ }^{34}$ John Whyte, Interpreting Northern Ireland. (Oxford: Clarendon Press, 1991 pp18-22).

${ }^{35}$ Robert D. Lowe and Orla T. Muldoon, "Religious and Ethnonational Identification and Political Violence," Ethnopolitics 9(1) (2010), pp. 71-83. 
${ }^{36}$ Jason Lyall, Graeme Blair, and Kosuke Imai, "Explaining Support for Combatants during Wartime: A Survey Experiment in Afghanistan," American Political Science Review 107(4) (2013), pp. 679-705.

${ }^{37}$ As suggested in literature on interviews with witnesses and victims of traumatic events (e.g., Kathleen Coulborn Faller, 2007. Interviewing Children about Sexual Abuse. Oxford University Press), asking specific detailed questions are likely to enhance recollection of adverse events in the past. This was particularly relevant for Catholics and Protestants in Northern Ireland, where the intensity of the Troubles was generally reduced postagreement, and the psychological immense difficulties remain. Psychological implications and complications are greater than they may seem. Subsequent to the NI peace agreement there were psychiatrists who were genuinely concerned that the postconflict burden of the conflict could be greater than it had been prior to the Agreement. Kathleen Coulborn Faller. Interviewing Children about Sexual Abuse (Oxford: Oxford University Press, 2007)

38 Edna B. Foa, David S. Riggs, Constance V. Dancu, and Barbara O. Rothbaum,"Reliability and Validity of a Brief Instrument for Assessing Post- Traumatic Stress Disorder," Journal of Traumatic Stress 6(4) (1993), pp. 459-473.

${ }^{39}$ Hall J. Brian, Stevan E. Hobfoll, Patrick A. Palmieri, Daphna Canetti- Nisim, Oren Shapira, Robert J. Johnson, and Sandro Galea, "The psychological impact of impending forced settler disengagement in Gaza: Trauma and posttraumatic growth," Journal of traumatic stress 21(1) (2008), pp. 22-29; Johnson, Howard, and Andrew Thompson, "The development and maintenance of post-traumatic stress disorder (PTSD) in civilian 
adult survivors of war trauma and torture: A review," Clinical psychology review 28(1) (2008): 36-47.

${ }^{40}$ Muldoon, T. Orla, Katharina Schmid, and Ciara Downes, "Political Violence and Psychological Well- Being: The Role of Social Identity," Applied Psychology 58(1) (2009): 129-145.

41 Leonie Huddy, Stanley Feldman, Theresa Capelos, and Colin Provost, "The Consequences of Terrorism: Disentangling the Effects of Personal and National Threat," Political Psychology 23(3) (2002), pp. 485-509; Cindy D. Kam and Donald R. Kinder, "Terror and Ethnocentrism: Foundations of American Support for the War on Terrorism," Journal of Politics 69(2) (2007), pp. 320-338.

${ }^{42}$ Daphna Canetti, Brian J. Hall, Carmit Rapaport, and Carly Wayne, "Exposure to Political Violence and Political Extremism," European Psychologist 18 (2013), pp. 263-272.

${ }^{43}$ This measure is different to the ones used in previous studies (Canetti et al. 2013; 2014) on EPV and willingness to compromise because it takes into account the different conflict settings in IL-PA and NI and therefore the differences between ongoing and post-conflict settings.

${ }^{44}$ This measure differs from the ones used in previous work on EPV and conciliatory attitudes (Daphna Canetti, Julia Elad-Strenger, Iris Lavi, Dana Guy, and Daniel Bar-Tal, "Exposure to Violence, Ethos of Conflict, and Support for Compromise Surveys in Israel, East Jerusalem, West Bank, and Gaza," Journal of Conflict Resolution 61(1) (2015), pp. 84-113) because it tailors its questions to the specific conflict-context; again looking at two different conflict settings simultaneously. 
${ }^{45}$ James L. Arbuckle, AMOS Development Corporation (Springhouse, Pennsylvania Patent AMOS 6.0, 2005).

${ }^{46}$ Barbara M. Byrne, "Testing for Multigroup Equivalence of a Measuring Instrument: A Walk through the Process," Psicothema 20(4) (2008), pp. 872-882.

${ }^{47}$ Karl G. Jöreskog and Dag Sörbom, LISREL 8: User's Reference Guide (Uppsala University: Scientific Software International, 1996); Rex B. Kline, Principles and Practice of Structural Equation Modeling (New York: The Guilford Press, 2005).

${ }^{48}$ Anne Boomsma, "Reporting Analyses of Covariance Structures," Structural Equation Modeling 7(3) (2000), pp. 461-483.

${ }^{49}$ Kenneth A. Bollen, "A New Incremental Fit Index for General Structural Equation Models," Sociological Methods \& Research 17(3) (1989), pp. 303-316.

${ }^{50}$ Nadim N. Rouhana, "Group Identity and Power Asymmetry in Reconciliation Processes: The Israeli-Palestinian Case," Peace and Conflict: Journal of Peace Psychology 10(1) (2004), pp. 33-52.

${ }^{51}$ Asher Arian, Security Threatened: Surveying Israeli Opinion on Peace and War (New York: Cambridge University Press, 1995); Asher Arian, Israeli Public Opinion on National Security 2003 (Tel Aviv: Tel Aviv University, Jaffe Center for Strategic Studies, 2003); Nurit Shnabel, Samer Halabi, and Masi Noor, "Overcoming Competitive Victimhood and Facilitating Forgiveness through Re-Categorization into a Common Victim or Perpetrator Identity," Journal of Experimental Social Psychology 49(5) (2013), pp. 867-877. 
${ }^{52}$ Roger MacGinty and Pierre Du Toit, "A Disparity of Esteem: Relative Group Status in Northern Ireland after the Belfast Agreement," Political Psychology 28(1) (2007), pp. 1331.

${ }^{53}$ Richard Haass, Beyond the INF Treaty: Arms, Arms Control, and the Atlantic Alliance (University Press of America, 1988); William Zartman, Ripe for Resolution: Conflict and Intervention in Africa (Oxford: Oxford University Press, 1988); William Zartman and Saadia Touval, "International Mediation: Conflict Resolution and Power Politics," Journal of Social Issues 41(2) (1985), pp. 27-45.

${ }^{54}$ Yaacov Bar-Siman-Tov (Ed.), Barriers to Peace in the Israeli-Palestinian Conflict (Jerusalem: Jerusalem Institute for Israel Studies, 2010); Corrina Carmen Gayer, Shiri Landman, Eran Halperin, and Daniel Bar-Tal, "Overcoming Psychological Barriers to Peaceful Conflict Resolution: The Role of Arguments about Losses," Journal of Conflict Resolution 53(6) (2009), pp. 951-975; Kristin M. Bakke, John O'Loughlin, and Michael D. Ward, "Reconciliation in Conflict-Affected Societies: Multilevel Modeling of Individual and Contextual Factors in the North Caucasus of Russia," Annals of the Association of American Geographers 99(5) (2009), pp. 1012-1021; Han Dorussen and Emil J. Kirchner, "Better a Good Neighbor than a Distant Friend: The Scope and Impact of Regional Security Organizations," International Relations of the Asia-Pacific 14(1) (2014), pp. 117-146; Eran Halperin and Daniel Bar-Tal, "Socio-Psychological Barriers to Peace Making: An Empirical Examination within the Israeli Jewish Society," Journal of Peace Research 48(5) (2011), pp. 637-651; Ifat Maoz, Andrew Ward, Michael Katz, and Lee Ross, "Reactive Devaluation of an "Israeli" vs. "Palestinian" Peace Proposal," Journal of Conflict Resolution 46(4) (2002), pp. 515-546. 
${ }^{55}$ Ronnie Janoff-Bulman, Shattered Assumptions: Towards a New Psychology of Trauma (New York: The Free Press, 1992).

${ }^{56}$ Daniel Bar-Tal, Intractable Conflicts: Socio-Psychological Foundations and Dynamics (New York: Cambridge University Press, 2013); Eran Halperin and Daniel Bar-Tal, "Socio-Psychological Barriers to Peace Making: An Empirical Examination within the Israeli Jewish Society," Journal of Peace Research 48(5) (2011), pp. 637-651; Roni Porat, Eran Halperin, and Daniel Bar-Tal, "The Effect of Sociopsychological Barriers on the Processing of New Information about Peace Opportunities," Journal of Conflict Resolution 59(1) (2015), pp. 93-119.

${ }^{57}$ Herbert C. Kelman, "The Interdependence of Israeli and Palestinian National Identities: The Role of the Other in Existential Conflicts," Journal of Social Issues 55(3) (1999), pp. 581-600; Ifat Maoz, "Multiple Conflicts and Competing Agendas: A Framework for Conceptualizing Structured Encounters between Groups in Conflict-The Case of a Coexistence Project of Jews and Palestinians in Israel," Peace and Conflict: Journal of Peace Psychology 6(2) (2000), pp. 135-156.

${ }^{58}$ Daniel Bar-Tal, Intractable Conflicts: Socio-Psychological Foundations and Dynamics (New York: Cambridge University Press, 2013); William Zartman, Ripe for Resolution: Conflict and Intervention in Africa (Oxford: Oxford University Press, 1989). 